Unternehmen suchen Sicherheit und Weltoffenheit

Es versteht sich von selbst, dass unsere Studie keine Aussagen über Einzelfälle erlaubt, sondern nur über Standortnachteile, die im konkreten Fall durch Vorteile ausgeglichen werden können. Viele bedeutende Unternehmensansiedlungen der letzten Jahre in den Neuen Ländern belegen dies. Gleichwohl sprechen alle Indikatoren aus unserer Befragung von Unternehmen dafür, dass Fremdenfeindlichkeit und rechte Gewalt den ostdeutschen Ländern besonders schaden. Unternehmen - West wie Ost - werten derartige regionale Belastungen eindeutig als Handicap für einen Standort. Bemerkenswerterweise war gerade unter den Unternehmen, die vor Ort arbeiten, den ostdeutschen Betrieben, die größte Unzufriedenheit gegenüber derartigen fremdenfeindlichen Ressentiments und rechtsradikal motivierten Übergriffen festzustellen. Man kann deshalb diese Problemsicht kaum als Ausfluss westlicher Vorurteile ansehen.

Besonders wichtig erscheint uns eine konsequente Thematisierung der Problematik im Kontext ihrer Zusammenhänge durch alle relevanten Akteure (Politik, Gewerkschaften und Wirtschaftsverbände). Denn das negative Bild gegenüber den Neuen Ländern in puncto Fremdenfeindlichkeit und rechter Gewalt hat sich in der Wirtschaft längst verfestigt, so dass jegliches Tabuisieren der Thematik kaum Abhilfe schaffen dürfte, sondern im Gegenteil, durch Schweigen wird der bereits bestehende schlechte Gesamteindruck nur perpetuiert.

Gezielte Wirtschaftsförderung und Standortmarketing sind zwar wichtig, aber sie könnten in vielen Regionen durch eine aktive Kriminalprävention unterstützt werden, zu denen vor allem die zahlreichen Aktionen und Initiativen gegen Fremdenfeindlichkeit und rechte Gewalt ${ }^{3}$ genauso wie bewusstseinschaffende Kampagnen in der Bevölkerung gehören. So betrachtet stellt eine gute Sozial- und Kriminalpolitik auch die notwendige Ergänzung einer effizienten Wirtschaftspolitik dar. Beide bedingen einander, wie die Ergebnisse der Studie gezeigt haben.

Im internationalen Standortwettbewerb gilt es für den Standort Deutschland mehr denn je Hochtechnologieunternehmen, Forschungs- und Entwicklungsbetriebe anzusiedeln. Um Missverständnissen vorzubeugen, Deutschland ist aus unserer Sicht in puncto innere Sicherheit im Osten wie im Westen international gut aufgestellt, aber Globalisierung und europäische Osterweiterung fordern in steigendem Maße eine weltoffene soziale Umgebung. Fremdenfeindlichkeit und rechte Gewalt verunsichern nicht nur nationale wie internationale Unternehmen, sondern sie können leicht mit einer gewissen Innovationsfeindlichkeit einer Region assoziiert werden.
Literatur

Polizeiliche Kriminalstatistik (2002): BKA Statistik, hrsg. vom Bundeskriminalamt. Berichtsjahr 2002, Wiesbaden.

Reuband, Karl-Heinz (1999): »Kriminalitätsfurcht. Stabilität und Wandel«, in: Neue Kriminalpolitik, S. 15-20.

Reuband, Karl-Heinz (2000): »Kriminalität als Thema ostdeutscher Massenmedien vor und nach der Wende. Eine Analyse Dresdner Tageszeitungen 1988-1994«, in: Kriminologisches Journal, S.43-55
Fußnoten:

1 Zur Relevanz der Medien in den Neuen Ländern siehe Reuband 2000.

$2 \mathrm{Um}$ diesen Vergleich $\mathrm{zu}$ ermöglichen, wurde zum Ausgleich der erheblich geringen Anzahl von F\&E Unternehmen in den Neuen Ländern deren Stichprobenanteil angehoben.

$3 \mathrm{Vgl}$. die umfangreichen Projektsammlungen im Internet; stellvertretend für viele andere: »Kommunale Datenbank gegen Gewalt, Extremismus und Fremdenfeindlichkeit « des Deutschen Städte- und Gemeindebundes (KODEX) unter www.dstgb.de/index_inhalt/homepage/artikel/brennpunkte/ kodex_datenbank_gegen_gewalt/index.html oder NetzGegenRechtsExtremismus.de.

TERMINAL

\title{
20 Jahre Sachbeschädigung "Aus der Sprühdose der Pandora*«
}

\author{
Von Gönke Jacobsen
}

Die Neue Kriminalpolitik widmet sich an dieser Stelle nicht nur der Verantwortung für Jugend, sondern erinnert an eine Jubiläum der Verantwortungslosigkeit: Seit 20 Jahren zieren Graffiti - Kunstwerk oder ist es nur purer Vandalismus? - deutsche S-Bahn-Züge. Was heute schon zum gewohnten, wenn auch meist nicht gewollten, Stadtbild gehört, begann im Jahr 1984 in München mit einem gesprayten Bild auf der S4 nach Gelten-dorf.

Ein paar Fakten: Den ersten Schriftzug - als Namenskürzel, in der Szene »tags « genannt, sprühte ein junger Grieche 1971 an New Yorker Wände: »Taki183«. Mittlerweile findet man den Sprühwahn auf der ganzen Welt. Er ist längst nicht mehr nur Ausdruck der HipHop-Kultur, sondern vielmehr Symbol der Jugend. Die Deutsche Bahn als Verlierer dieser Bewegung hat deshalb heute einen achtstelligen Geldbetrag für die Graffitibekämpfung in ihrem Haushalt vorgesehen. Die Entfernung eines 56 Meter langen »piece« war der Bahn im Jahr 1985 beispielsweise 6.000 Mark wert. Dabei wächst die Gruppe der meist jugendlichen Sprayer kontinuierlich an: von 1998 bis 2002 in und um München um 36,5 \% auf 12.347 Taten.

Mittlerweile hat die Polizei Sonderkommissionen zur Sichtung der Graffiti-Szene eingesetzt oder Netzwerke für Hausbesitzer initiiert. Diese sollen auf der einen Seite Kunstkenner, sprich also Kunstwiedererkenner sein, und auf der anderen Seite die Straftaten der Sprayer verfolgen und enttarnen und die zivilrechtlichen Ansprüche der Hausbesitzer sichern: welch ungewöhnlicher Zug zu praktischer Opferhilfe!

An dieser Stelle deshalb auch ein Dank an die Münchner Polizei: Nachdem der Fotograph der Neuen Kriminalpolitik den »Muskelmann « auf S. 100 in seinem Kasten hatte, folgte prompt eine Personenuntersuchung durch besagte Kunstkenner, welche erfreut waren, dass es sich um ein Pressefoto für eine kriminalpolitische Zeitung und nicht um eine Selbstdokumentation des Sprayers handelte. Sie waren sofort sehr kooperativ: Natürlich gäbe es beeindruckende Exponate zu bewundern; ein individueller Studienrundgang konnte ohne Probleme zusammengestellt werden.

Nun, an wen richtet man den Glückwunsch? An die Graffiti-Sprayer, deren Lebensgefühl weiter an Wänden ihren Ausdruck findet; an die Bahn, die weiter einen Kampf gegen Windmühlen führt; oder an die Kriminalpolitik, die zwischen Entkriminalisierung und repressiven Druck einen Spagat versucht? Vielleicht muss die Gratulation gerecht unter den Beteiligten aufgeteilt werden: Erst das Zusammenwirken macht letzendlich den »Thrill« des Graffiti-Sprayen aus.

* So titelte die tazzwei am 30. Juni 2004, S. 13. Für weitere Informationen sei auf diesen Artikel verwiesen. 